\title{
The prevalence of diabetes mellitus with chronic kidney disease in adults and associated factors in Songjiang District, Shanghai
}

\author{
Yu Yang ${ }^{1}$, Na Wang ${ }^{1}$, Yonggen Jiang ${ }^{2}$, Qi Zhao ${ }^{1}$, Yue Chen ${ }^{3}$, Xiaohua Ying ${ }^{1}$, Genming Zhao ${ }^{1}$, Chaowei Fu ${ }^{1}$ \\ ${ }^{1}$ School of Public Health; Key Laboratory of Public Health Safety, NHC Key Laboratory of Health Technology Assessment, Fudan University, \\ Shanghai, China; ${ }^{2}$ Songjiang Disease Prevention and Control Center, Shanghai, China; ${ }^{3}$ School of Epidemiology and Public Health, Faculty of \\ Medicine, University of Ottawa, Ottawa, Canada \\ Contributions: (I) Conception and design: C Fu, Q Zhao, Y Chen; (II) Administrative support: Y Jiang, X Ying, G Zhao; (III) Provision of study \\ materials or patients: N Wang, Y Jiang, G Zhao; (IV) Collection and assembly of data: N Wang, Y Jiang, Q Zhao, X Ying, G Zhao; (V) Data analysis \\ and interpretation: Y Yang, N Wang, Y Chen, C Fu; (VI) Manuscript writing: All authors; (VII) Final approval of manuscript: All authors. \\ Correspondence to: Chaowei Fu. School of Public Health, Key Laboratory of Public Health Safety, NHC Key Laboratory of Health Technology \\ Assessment, Fudan University, Shanghai 200032, China. Email: fcw@fudan.edu.cn.
}

\begin{abstract}
Background: Diabetes mellitus (DM) complicated with chronic kidney disease (CKD) has been a severe public health issue in China. This study aimed to investigate the prevalence of adult DM complicated with CKD and its associated factors in Songjiang District, Shanghai.

Methods: A large-scale community-based cross-sectional study was conducted among 36,077 participants aged 20-74 years in Songjiang District, Shanghai between June 2016 and December 2017. Epidemiological data of the Shanghai Suburban Adult Cohort and Biobank (SSACB) and electronic health record (EHR) data based on the big data platform of Songjiang District were combined to estimate the prevalence of adult DM with CKD. Factors associated with DM complicated with CKD were analyzed by using univariate and multivariate logistic regression models with adjusted odds ratios (aOR) and their $95 \%$ confidence intervals (CI).

Results: The overall prevalence of adult DM with CKD among the community population in Songjiang District, Shanghai was $2.9 \%$ (95\% CI: $2.8-3.1 \%)$. The prevalence significantly increased with age and the prevalence was significantly lower than in men than in women $(2.4 \%$ vs. $3.3 \%, \mathrm{P}<0.001)$. Factors were positively associated with adult DM with CKD including female (aOR: 1.40; 95\% CI: 1.13-1.72), older age (aOR for 40-59 years age group: 3.85; 95\% CI: $1.92-7.72$; aOR for $\geq 60$ years age group: $6.17 ; 95 \%$ CI: 3.05-12.47), urban community (aOR: 1.61; 95\% CI: 1.38-1.87), HbAlc $\geq 6.5 \%$ (aOR: 24.01; 95\% CI: 20.59-28.01), hypertension (aOR: 2.16; 95\% CI: 1.77-2.64), dyslipidemia (aOR: 1.58; 95\% CI: 1.35-1.84), coronary heart disease (CHD, aOR: 2.15; 95\% CI: 1.84-2.52), hyperuricemia (aOR: 1.61; 95\% CI: 1.36-1.90) and family history of DM (aOR: 2.73; 95\% CI: 2.26-3.29). In sensitivity analysis, those factors except female and urban community were still positively associated with adult DM with CKD.

Conclusions: DM with CKD was common among adults in Songjiang District, Shanghai. Effective public health programs should be developed to control DM with CKD for targeted populations.
\end{abstract}

Keywords: Diabetes mellitus (DM); chronic kidney disease (CKD); prevalence; Chinese

Submitted Apr 05, 2021. Accepted for publication Jun 05, 2021.

doi: $10.21037 / \mathrm{apm}-21-803$

View this article at: https://dx.doi.org/10.21037/apm-21-803

^ ORCID: 0000-0002-3869-2060. 


\section{Introduction}

Diabetes mellitus (DM) is an important public health problem worldwide. Diabetic kidney disease (DKD) is one of the most common microvascular complications of DM and is currently the leading cause of end-stage renal disease (ESRD) in developed counties (1). In China, DKD ranks after glomerulonephritis as the second leading cause of ESDR (2). Besides, patients with chronic kidney disease (CKD) are at high risk of late-onset diabetes (3). Factors including age, sex, hypertension, body mass index (BMI), hyperuricemia, glycated hemoglobin (HbA1c) and dyslipidemia influence the development and progress of DM complicated with CKD (4-7).

There have been few studies investigating the prevalence of DM with CKD patients in China. One study from 35.3 million DM inpatients in tertiary hospitals between 2010 and 2015 estimated that $21.3 \%$ were complicated with CKD in China (8), and small-scale studies of community population suggested that about 30-40\% DM patients were complicated with CKD in Shanghai $(9,10)$. Another large-scale cross-sectional survey of Chinese rural residents in Henan province estimated a prevalence of DM with CKD being $2.9 \%$ (11). In the current study, we aimed to determine the prevalence of DM with CKD and its associated factors among adults living in urban-rural mixed area of Songjiang District, Shanghai. We used baseline data of the Shanghai Suburban Adult Cohort and Biobank (SSACB) combined with electronic health record (EHR) data from the Songiiang District health data platform. We present the following article in accordance with the STROBE reporting checklist (available at https:// dx.doi.org/10.21037/apm-21-803).

\section{Methods}

\section{Study population}

Data from the baseline survey of the Shanghai Suburban Adult Cohort Study were collected during the period from June 2016 to December 2017. Multistage stratified sampling method was employed to select subjects dwelled in four communities of Songjiang District, including two urban communities (Zhongshan and Xinqiao), and two non-urban community (Sheshan and Maogang), which had been described previously (12). Inclusion criteria were as follows: (I) aged between 20 and 74; (II) lived in those communities for at least 6 months and had no plan to move in the next year; (III) had no disabilities, terminal illness or perceptual impairment; (IV) provided written informed consent before data collection. A total of 37,670 subjects were recruited with the response rate of $95.8 \%$, and of them, 36,077 subjects completed the questionnaire and free physical examinations. All procedures performed in this study involving human participants were in accordance with the Declaration of Helsinki (as revised in 2013). The study was approved by the ethical committee of School of Public Health, Fudan University (IRB approval number 2016-040586). Written informed consent was given by all individual participants.

\section{Questionnaire interview}

All the subjects completed a standardized questionnaire by a face-to-face interview. Data collected included demographic characteristics (e.g., age, sex, educational level), personal and family history of chronic diseases (e.g., diabetes, hypertension, coronary heart disease, hepatitis, CKD), lifestyle (e.g., smoking, alcohol consumption, physical activity) and dietary patterns. Anthropometric measurements including height, weight, waist circumference (WC), blood pressure (BP) and heart rate (HR) were obtained using standard techniques and protocols. BMI $\left(\mathrm{kg} / \mathrm{m}^{2}\right)$ was calculated as weight in kilograms divided by height in meter squared. Standard techniques and protocols of the questionnaire survey and anthropometric measurements had also been described previously (12).

\section{Laboratory assays}

Blood and urine specimens were collected and stored at $-80{ }^{\circ} \mathrm{C}$ freezer within less than $6 \mathrm{~h}$. Biochemistry parameters were measured at the Shanghai Dian Diagnostics Co Ltd. Blood biochemical indicator including fasting plasma glucose (FPG), HbA1c, serum total cholesterol (TC), triglyceride (TG), high-density lipoprotein cholesterol (HDL-C), low-density lipoprotein cholesterol (LDL-C), serum uric acid (SUA) and serum creatinine (SCr) were measured. Urine biochemical indicators including microscopic red blood cell and microscopic white blood cell were measured (12).

\section{Health data platform}

A health data platform was established in 2018 to integrate the SSACB database with EHR databases for all the residents from the four communities in Songjiang District with a unique identification number. We also linked the 
records in the SSACB database to the other databases including the databases of diabetes report, clinical diagnosis and clinical laboratory examination for information recorded before December 31, 2017 to supplement DM and CKD diagnoses as well as other personal health information.

\section{Definitions}

DM was defined by the WHO 1999 criteria (13): FPG $\geq 7.0 \mathrm{mmol} / \mathrm{L}$ and/or receiving antidiabetic treatment and/ or a previous diagnosis of DM. According to the 2012 Kidney Disease: Improving Global Outcomes (KDIGO) guidelines (14), CKD was defined as $\geq 1$ of the following abnormal kidney structure or function: (I) hematuria, [ $>3$ red blood cells per high power field (RBCs/HPF)]; (II) leukocyturia [ $>5$ white blood cells per high power field (WBCs/HPF)]; (III) albuminuria [urinary albumin/creatinine ratio (ACR) $\geq 30 \mathrm{mg} / \mathrm{g}$ or the qualitative test of urinary proteins was positive]; (IV) estimated glomerular filtration rate (eGFR) $<60 \mathrm{~mL} / \mathrm{min}$ per $1.73 \mathrm{~m}^{2}$; (V) history of kidney transplantation; (VI) a previous diagnosis of CKD. SCr was measured by enzymatic methods. Chinese simplified Modification of Diet in Renal Disease (MDRD) equation was used to calculate eGFR: eGFR $=175 \times \mathrm{Scr}(\mathrm{mg} / \mathrm{dL})^{-1.234} \times$ $\operatorname{age}^{-0.179}(\times 0.79$ in female $)(15)$. The diagnosis of acute nephropathy was excluded based on the clinical diagnosis record. Hypertension was defined as systolic BP (SBP) $\geq 140 \mathrm{mmHg}$ and/or diastolic BP (DBP) $\geq 90 \mathrm{mmHg}$ and/ or receiving antihypertensive treatment and/or a previous diagnosis of hypertension (16). Hyperuricemia was defined as SUA $>420 \mu \mathrm{mol} / \mathrm{L}(7.0 \mathrm{mg} / \mathrm{dL})$ for men and $>360 \mu \mathrm{mol} / \mathrm{L}$ $(6.0 \mathrm{mg} / \mathrm{dL})$ for women and/or a previous diagnosis of hyperuricemia (17). Dyslipidemia was defined as one of the following criteria: (I) $\mathrm{TC} \geq 6.22 \mathrm{mmol} / \mathrm{L}$; (II) LDL-C $\geq 4.14 \mathrm{mmol} / \mathrm{L}$; (III) HDL-C $<1.04 \mathrm{mmol} / \mathrm{L}$; (IV) TG $\geq 2.26 \mathrm{mmol} / \mathrm{L}$; (V) a previous diagnosis of hyperlipidemia (18). BMI was classified into four levels based on the WHO criteria: underweight (BMI $\left.<18.5 \mathrm{~kg} / \mathrm{m}^{2}\right)$; normal $\left(18.5 \leq \mathrm{BMI}<25 \mathrm{~kg} / \mathrm{m}^{2}\right)$; overweight $\left(25 \leq \mathrm{BMI}<30 \mathrm{~kg} / \mathrm{m}^{2}\right)$ and obese (BMI $\geq 30 \mathrm{~kg} / \mathrm{m}^{2}$ ) (19). The sensitivity analysis used a narrower definition for CKD: (I) albuminuria (ACR $\geq 30 \mathrm{mg} / \mathrm{g}$ or the qualitative test of urinary proteins was positive); (II) eGFR $<60 \mathrm{~mL} / \mathrm{min}$ per $1.73 \mathrm{~m}^{2}$.

\section{Statistical analysis}

Data were double-entered using Epidata version 3.1 and analyzed using SPSS version 23.0 (IBM Corp, Armonk, New York, USA) and R version 3.6.0 (R Foundation for Statistical Computing, Vienna, Austria). Continuous variables were expressed as means \pm standard deviations (SD) and categorical variables as frequencies and percentages. Student's $t$-test, Wilcoxon test, Mann-Whitney U-test, analysis of variance (ANOVA), Chi-square test were used for intergroup comparisons depending on data types. Univariate and multivariate logistic regression was used to identify factors related to DM with CKD and estimate the crude odds ratios (OR), adjusted odds ratios (aOR) and their corresponding $95 \%$ confidence intervals (CI). $\mathrm{P}$ value $<0.05$ was considered to be statistically significant.

\section{Results}

\section{General characteristics of study population}

The social-demographic and clinical characteristics of subjects were shown in Table 1. Among 36,077 subjects, 4,024 had DM only, 4,496 had CKD only, and 1,057 had both $\mathrm{DM}$ and $\mathrm{CKD}$, with an average age of $56.7 \pm 11.2$ years. Overall, more than two fifth $(42.5 \%)$ were urban community residents. The prevalences of four major chronic diseases (rating from high to low) were as follows: hypertension $(57.4 \%)$, dyslipidemia (38.7\%), coronary heart disease (CHD, 23.6\%), and hyperuricemia (17.7\%). There were significant differences in age, sex, education, smoking status, alcohol drinking, regular exercise, BMI, prevalence of four major chronic diseases and urban community $(\mathrm{P}<0.001)$ of four groups.

\section{Prevalence of DM with CKD in different sex and age groups}

The overall prevalence of DM with CKD was 2.9\% (95\% CI: $2.8-3.1 \%$ ) among this community population. The prevalence of DM with CKD significantly increased with age $(\mathrm{P}<0.001)$ and reached at $4.4 \%$ for those aged 60 years or above. The prevalence was significantly lower in men compared with women $(2.4 \%$ versus $3.3 \%, \mathrm{P}<0.001)$. Figure 1 shows the sex and age specific prevalence of DM with CKD.

\section{Related factors of DM with CKD}

Univariate and multivariate logistic regression included no DM or CKD group and DM with CKD group. Sex, 
Table 1 Baseline social-demographic and clinical characteristics of the SSACB population

\begin{tabular}{|c|c|c|c|c|c|c|}
\hline Characteristics & $\begin{array}{c}\text { Total } \\
(\mathrm{n}=36,077)\end{array}$ & $\begin{array}{c}\text { No DM or CKD } \\
(n=26,500)\end{array}$ & $\begin{array}{l}\text { DM only } \\
(n=4,024)\end{array}$ & $\begin{array}{l}\text { CKD only } \\
(n=4,496)\end{array}$ & $\begin{array}{l}\text { DM with CKD } \\
\quad(n=1,057)\end{array}$ & $P$ value \\
\hline Age (years) & $56.7 \pm 11.2$ & $55.6 \pm 11.6$ & $60.8 \pm 7.7$ & $58.2 \pm 10.8$ & $62.9 \pm 7.4$ & $<0.001$ \\
\hline Male & $14,626(40.5)$ & $11,280(42.6)$ & $1,833(45.6)$ & 1,162 (25.8) & $351(33.2)$ & \\
\hline$\leq 9$ education years & $30,458(84.4)$ & $21,909(82.7)$ & $3,632(90.3)$ & $3,947(87.8)$ & $3,632(91.8)$ & \\
\hline$>9$ education years & $5,619(15.6)$ & 4,591 (17.3) & $392(9.7)$ & 549 (12.2) & $87(8.2)$ & \\
\hline Smoking status, $\mathrm{n}(\%)$ & & & & & & $<0.001$ \\
\hline Alcohol drinking, n (\%) & & & & & & $<0.001$ \\
\hline Current & 4,485 (12.4) & $3,478(13.1)$ & $598(14.9)$ & $320(7.1)$ & $89(8.4)$ & \\
\hline Former & $399(1.1)$ & $256(1.0)$ & $72(1.8)$ & $53(1.2)$ & $18(1.7)$ & \\
\hline Never & $31,193(86.5)$ & 22,766 (85.9) & 3,354 (83.3) & $4,123(91.7)$ & $950(89.9)$ & \\
\hline Regular exercise, n (\%) & & & & & & $<0.001$ \\
\hline Yes & $11,548(32.0)$ & $8,364(31.6)$ & $1,389(34.5)$ & $1,417(31.5)$ & $378(35.8)$ & \\
\hline No & $24,529(68.0)$ & $18,136(68.4)$ & $2,635(65.5)$ & $3,079(68.5)$ & $679(64.2)$ & \\
\hline Hypertension, n (\%) & $20,703(57.4)$ & $13,928(52.6)$ & $3,176(78.9)$ & $2,701(60.1)$ & $898(85.0)$ & $<0.001$ \\
\hline Dyslipidemia, n (\%) & $13,952(38.7)$ & $9,296(35.1)$ & $2,203(54.7)$ & $1,788(39.8)$ & $665(62.9)$ & $<0.001$ \\
\hline $\mathrm{CHD}, \mathrm{n}(\%)$ & $8,522(23.6)$ & $5,175(19.5)$ & $1,458(36.2)$ & $1,356(30.2)$ & $533(50.4)$ & $<0.001$ \\
\hline Hyperuricemia, n (\%) & $6,384(17.7)$ & $4,279(16.1)$ & 735 (18.3) & $1,027(22.8)$ & $343(32.5)$ & $<0.001$ \\
\hline Urban community & $15,343(42.5)$ & $10,940(41.3)$ & $1,735(43.1)$ & $2,126(47.3)$ & $542(51.3)$ & $<0.001$ \\
\hline
\end{tabular}

$\mathrm{P}$ value $<0.05$ means the significant difference over four groups. ${ }^{a}$, BMI had 596 missing values. BMI, body mass index; CHD, coronary heart disease; CKD, chronic kidney disease; DM, diabetes mellitus.

age, education levels, urban community, BMI, smoking status, alcohol drinking, regular physical exercise, HbA1c, hypertension, dyslipidemia, CHD, hyperuricemia, family history of DM were significantly related to DM with CKD. After the adjustment for covariates, they were still significantly related to $\mathrm{DM}$ with $\mathrm{CKD}$ except for education levels, BMI, smoking status, alcohol drinking and regular physical exercise (Table 2). Women (aOR: 1.40; 95\% CI: $1.13-1.72$ ), older age (aOR for 40-59 years age group: 3.85 ; $95 \%$ CI: $1.92-7.72$; aOR for $\geq 60$ years age group: 


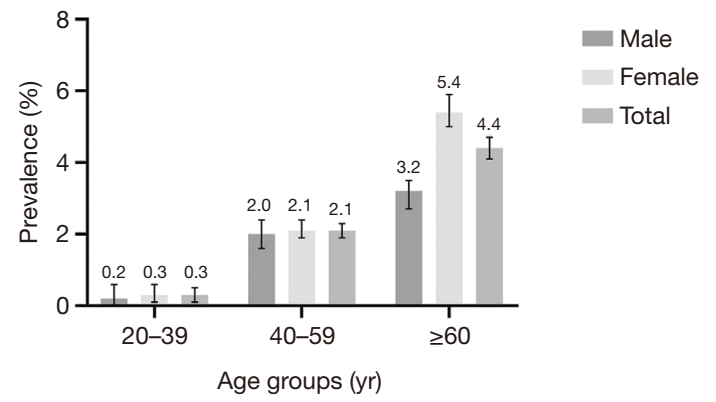

Figure 1 Prevalence of DM with CKD in male and female increased with age groups. The error bars mean $95 \%$ confidence intervals. DM, diabetes mellitus; CKD, chronic kidney disease.

6.17; 95\% CI: 3.05-12.47), urban community (aOR: 1.61; 95\% CI: $1.38-1.87$ ), HbAlc $\geq 6.5 \%$ (aOR: 24.01 ; 95\% CI: 20.59-28.01), hypertension (aOR: 2.16; 95\% CI: 1.77-2.64), dyslipidemia (aOR: 1.58; 95\% CI: 1.35-1.84), CHD (aOR: 2.15; 95\% CI: 1.84-2.52), hyperuricemia (aOR: 1.61; 95\% CI: $1.36-1.90)$ and family history of DM (aOR: 2.73 ; $95 \%$ CI: 2.26-3.29) were independent risk factors for DM with CKD. In sensitivity analysis, older age (aOR for $\geq 60$ years age group: 4.02 ; $95 \%$ CI: $1.22-13.25$ ), $\mathrm{HbAlc} \geq 6.5 \%$ (aOR: 30.89; 95\% CI: 24.57-38.83), hypertension (aOR: 2.81; 95\% CI: 1.98-4.00), dyslipidemia (aOR: 1.71; 95\% CI: 1.34-2.17), CHD (aOR: 1.98; 95\% CI: 1.57-2.49), hyperuricemia (aOR: 2.19; 95\% CI: $1.74-2.77$ ) and family history of DM (aOR: 2.80; 95\% CI: 2.13-3.68) were independent risk factors for DM with CKD (Table 3).

\section{Discussion}

This study demonstrated that the prevalence of CKD among DM patients was $20.8 \%$ and the prevalence of DM with CKD was $2.9 \%$ among the community population in Songjiang District, Shanghai, compared with $20-40 \%$ from other Chinese studies (8-10). In the United States, CKD prevalence was $26.2 \%$ among adults with DM (1). A cross-sectional survey conducted among rural adult residents in Henan province from July 2015 to December 2017 showed that the prevalence of DKD, or DM complicated with CKD, was $2.9 \%$, which was similar to our result. The prevalence of DKD in the US population was $3.3 \%$ according to the National Health and Nutrition Examination Survey (NHANES) 2005-2008 (20). Most epidemiological surveys on DKD measured DM complicated with CKD and the diagnostic criteria on CKD only included albuminuria and decreased eGFR. Our study used more comprehensive diagnostic criteria including hematuria, leukocyturia, history of kidney transplantation based on 2012 KDIGO guidelines. The application of EHR databases had improved the diagnoses.

Previous studies have provided inconsistent results for the sex difference in DM with CKD. Some studies showed that poor metabolic control and renal function decline were more common in women than men $(5,21,22)$ and postmenopausal women with DM reported to be at a higher risk of hyperuricemia, higher BMI and dyslipidemia that led to decreased renal function (23), while some studies showed that men were at a higher risk or there was no sex difference in DM with CKD patients (24-26). In this study, women were more likely to have DM with CKD. Also, the prevalence of DM with CKD significantly increased with age and possible explanations included worse renal function and more complications such as hypertension and diabetes as aging $(4,27)$. Figure 1 revealed that the prevalence of DM with $\mathrm{CKD}$ was higher in women only for $\geq 60$ years group, whereas for all other age groups, the $95 \%$ CI between men and women overlaped. More than 60 years age group was a large group in this population (44.5\%) and second only to $40-59$ years age group (45.6\%), which might explain the overall higher prevalence in women than men. However, female was not independent risk factors in sensitivity analysis. Also, urban community was an independent risk factors for DM or with CKD in main results but not significant in sensitivity analysis. Urban population had better health service accessibility, which may raise disease detection rate (28). Lifestyle factors including smoking and alcohol drinking may not be independent risk factors for DM with CKD unless large amounts were consumed (29-31). Case-control studies found no significant association between smoking and CKD $(32,33)$. Moderate alcohol consumption might be of potential benefit for CKD instead by increasing several HDL cholesterol subfractions $(34,35)$. Our results also showed that HbA1c $\geq 6.5 \%$, hypertension, dyslipidemia, CHD, hyperuricemia, family history of DM were possible risk factors of $\mathrm{DM}$ with $\mathrm{CKD}$, which were consistent with previous studies (36-40).

This study was the first representative large-scale community-based cross-sectional survey on the prevalence of DM with CKD and associated factors in Shanghai. Standard protocol and strict quality control were used to ensure reliable results. In addition, this study integrated epidemiological data of SSACB with EHR data based on the big data platform of Songiiang District, which provided more comprehensive information on diagnosis of diseases 
Table 2 Univariate and multivariate logistic regression analysis of factors related to DM with CKD

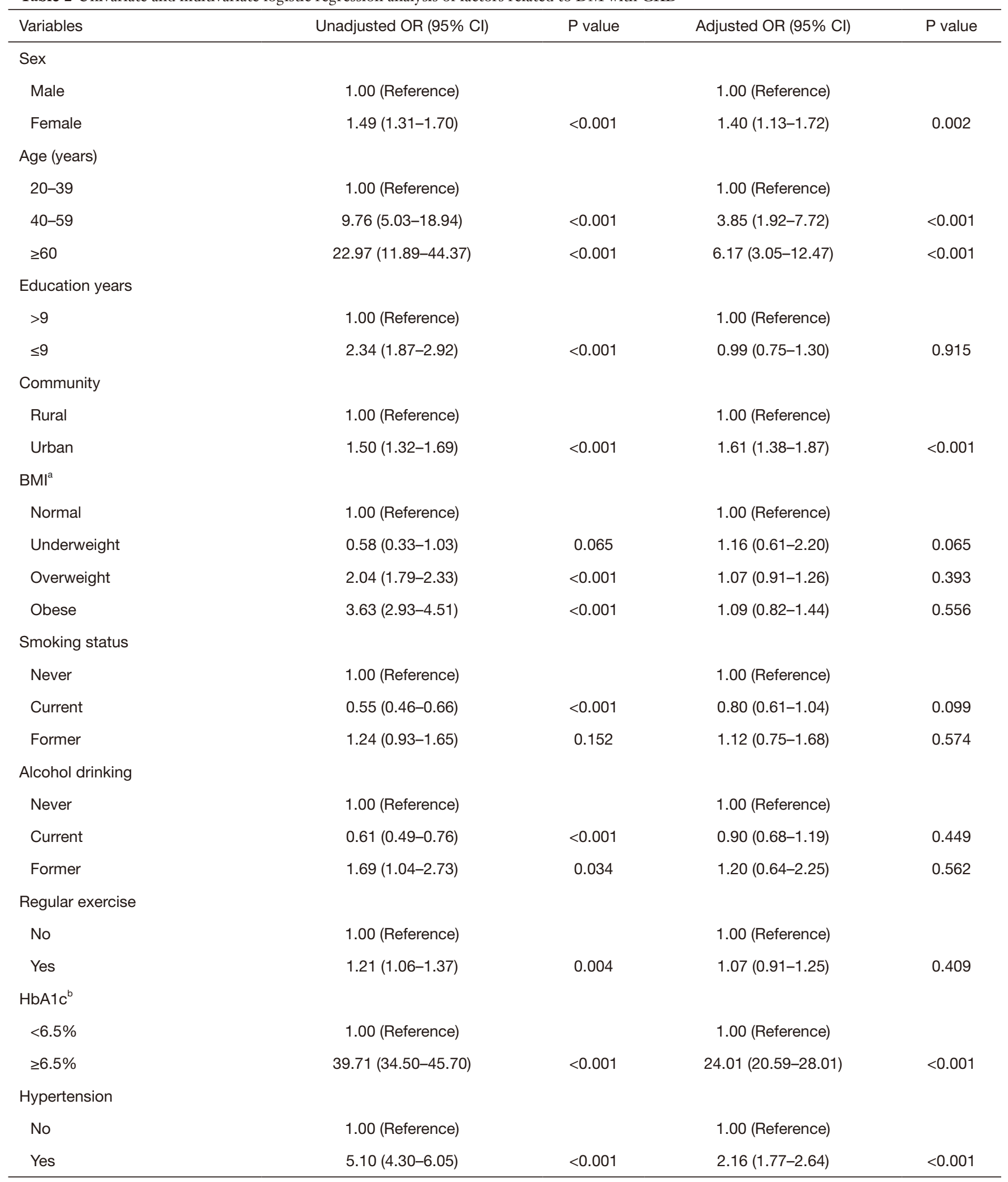

Table 2 (continued) 
Table 2 (continued)

\begin{tabular}{|c|c|c|c|c|}
\hline Variables & Unadjusted OR (95\% Cl) & $P$ value & Adjusted OR (95\% Cl) & $P$ value \\
\hline \multicolumn{5}{|c|}{ Dyslipidemia } \\
\hline No & 1.00 (Reference) & & 1.00 (Reference) & \\
\hline Yes & $3.14(2.76-3.57)$ & $<0.001$ & $1.58(1.35-1.84)$ & $<0.001$ \\
\hline \multicolumn{5}{|l|}{ CHD } \\
\hline Yes & $4.19(3.70-4.75)$ & $<0.001$ & $2.15(1.84-2.52)$ & $<0.001$ \\
\hline \multicolumn{5}{|c|}{ Hyperuricemia } \\
\hline No & 1.00 (Reference) & & 1.00 (Reference) & \\
\hline Yes & $2.50(2.18-2.85)$ & $<0.001$ & $1.61(1.36-1.90)$ & $<0.001$ \\
\hline Yes & $3.19(2.76-3.69)$ & $<0.001$ & $2.73(2.26-3.29)$ & $<0.001$ \\
\hline
\end{tabular}

Unadjusted OR was estimated from the univariate logistic regression model and adjusted OR was estimated from the multivariate logistic regression model with all the variables listed in the table. $\mathrm{P}$ value $<0.05$ means the significant correlation coefficient. ${ }^{a}$, BMI had 460 missing values. ${ }^{b}, \mathrm{HbA} 1 \mathrm{c}$ had 317 missing values. BMI, body mass index; CHD, coronary heart disease; CKD, chronic kidney disease; DM, diabetes mellitus; HbA1c, glycated hemoglobin.

Table 3 Sensitivity analysis of univariate and multivariate logistic regression analysis of factors related to DM with CKD

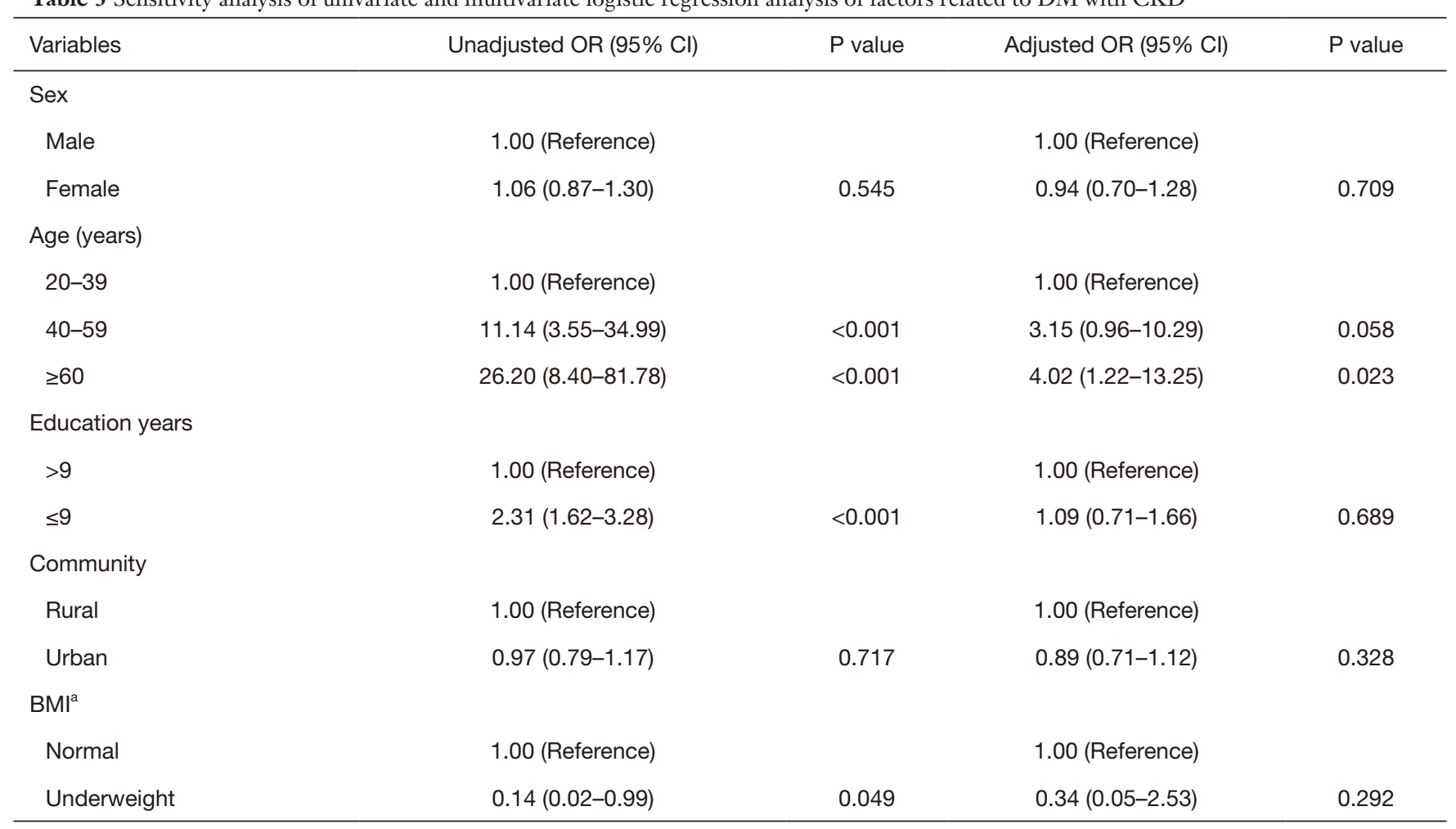

Table 3 (continued) 
Table 3 (continued)

\begin{tabular}{|c|c|c|c|c|}
\hline Variables & Unadjusted OR $(95 \% \mathrm{Cl})$ & $P$ value & Adjusted OR (95\% Cl) & $P$ value \\
\hline Obese & $5.50(4.04-7.48)$ & $<0.001$ & $1.36(0.94-1.98)$ & 0.103 \\
\hline \multicolumn{5}{|c|}{ Smoking status } \\
\hline Never & 1.00 (Reference) & & 1.00 (Reference) & \\
\hline Former & $1.64(1.08-2.47)$ & 0.019 & $1.39(0.81-2.38)$ & 0.235 \\
\hline \multicolumn{5}{|c|}{ Alcohol drinking } \\
\hline Never & 1.00 (Reference) & & 1.00 (Reference) & \\
\hline Current & $0.68(0.49-0.96)$ & 0.028 & $0.78(0.51-1.19)$ & 0.244 \\
\hline No & 1.00 (Reference) & & 1.00 (Reference) & \\
\hline Yes & $1.15(0.94-1.41)$ & 0.173 & $1.02(0.81-1.29)$ & 0.860 \\
\hline \multicolumn{5}{|l|}{$\mathrm{HbA} 1 \mathrm{c}^{\mathrm{b}}$} \\
\hline$<6.5 \%$ & 1.00 (Reference) & & 1.00 (Reference) & \\
\hline$\geq 6.5 \%$ & $54.42(44.00-67.32)$ & $<0.001$ & 30.89 (24.57-38.83) & $<0.001$ \\
\hline \multicolumn{5}{|l|}{ Hypertension } \\
\hline No & 1.00 (Reference) & & 1.00 (Reference) & \\
\hline Yes & $7.78(5.67-10.67)$ & $<0.001$ & $2.81(1.98-4.00)$ & $<0.001$ \\
\hline Yes & $4.15(3.42-5.04)$ & $<0.001$ & $1.98(1.57-2.49)$ & $<0.001$ \\
\hline \multicolumn{5}{|l|}{ Hyperuricemia } \\
\hline No & 1.00 (Reference) & & 1.00 (Reference) & \\
\hline Yes & 3.97 (3.27-4.83) & $<0.001$ & $2.19(1.74-2.77)$ & $<0.001$ \\
\hline \multicolumn{5}{|c|}{ Family history of DM } \\
\hline No & 1.00 (Reference) & & 1.00 (Reference) & \\
\hline Yes & $3.31(2.65-4.12)$ & $<0.001$ & $2.80(2.13-3.68)$ & $<0.001$ \\
\hline
\end{tabular}

Unadjusted OR was estimated from the univariate logistic regression model and adjusted OR was estimated from the multivariate logistic regression model with all the variables listed in the table. $\mathrm{P}$ value $<0.05$ means the significant correlation coefficient. ${ }^{a}$, BMI had 504 missing values. ${ }^{b}$, HbA1c had 339 missing values. BMI, body mass index; CHD, coronary heart disease; CKD, chronic kidney disease; DM, diabetes mellitus; HbA1c, glycated hemoglobin. 
and other personal health information to control possible information bias.

There were several limitations for this study. Firstly, it was impossible to infer a causal relationship between DM with CKD and associated factors with the cross-sectional design. Secondly, diagnostic indicators based on a single measurement were not confirmed after 3 months, and the prevalence of DM with CKD may be overestimated or underestimated in this study. Thirdly, urinary ACR was only available for those who had EHR data of clinical laboratory examinations, and albuminuria could be underdiagnosed.

\section{Conclusions}

The prevalence of DM complicated with CKD in adults was 2.9\% (95\% CI: 2.8-3.1\%) in Songjiang District, Shanghai. DM with CKD were positively associated with female, older age, HbA1c $\geq 6.5 \%$, hypertension, dyslipidemia, CHD, hyperuricemia and family history of DM. It is important to develop effective public health programs to control the DM with CKD for targeted populations.

\section{Acknowledgments}

The authors thank all participants in this study, as well as all data managers and clinical staff who make the study possible.

Funding: This study was supported by grants from the National Key Research and Development Program of China (2016YFC1305503) and Shanghai Municipal Education Commission-Gaofeng Discipline Development Project for Public Health and Preventive Medicine (No.17).

\section{Footnote}

Reporting Checklist: The authors have completed the STROBE reporting checklist. Available at https://dx.doi. org/10.21037/apm-21-803

Data Sharing Statement: Available at https://dx.doi. org/10.21037/apm-21-803

Peer Review File: Available at https://dx.doi.org/10.21037/ apm-21-803

Conflicts of Interest: All authors have completed the ICMJE uniform disclosure form (available at https://dx.doi. org/10.21037/apm-21-803). The authors report that they received grant from National Key Research and Development Program of China (2016YFC1305503) and Shanghai Municipal Education Commission-Gaofeng Discipline Development Project for Public Health and Preventive Medicine (No.17).

Ethical Statement: The authors are accountable for all aspects of the work in ensuring that questions related to the accuracy or integrity of any part of the work are appropriately investigated and resolved. All procedures performed in this study involving human participants were in accordance with the Declaration of Helsinki (as revised in 2013). The study was approved by the ethical committee of School of Public Health, Fudan University (IRB approval number 2016-04-0586). Written informed consent was given by all individual participants.

Open Access Statement: This is an Open Access article distributed in accordance with the Creative Commons Attribution-NonCommercial-NoDerivs 4.0 International License (CC BY-NC-ND 4.0), which permits the noncommercial replication and distribution of the article with the strict proviso that no changes or edits are made and the original work is properly cited (including links to both the formal publication through the relevant DOI and the license). See: https://creativecommons.org/licenses/by-nc-nd/4.0/.

\section{References}

1. Koye DN, Magliano DJ, Nelson RG, et al. The Global Epidemiology of Diabetes and Kidney Disease. Adv Chronic Kidney Dis 2018;25:121-32.

2. Zuo L, Wang M, Chinese Association of Blood Purification Management of Chinese Hospital A. Current burden and probable increasing incidence of ESRD in China. Clin Nephrol 2010;74 Suppl 1:S20-2.

3. Lin CY, Hsieh MC, Kor CT, et al. Association and risk factors of chronic kidney disease and incident diabetes: a nationwide population-based cohort study. Diabetologia 2019;62:438-47.

4. Glassock RJ, Winearls C. Ageing and the glomerular filtration rate: truths and consequences. Trans Am Clin Climatol Assoc 2009;120:419-28.

5. Kajiwara A, Kita A, Saruwatari J, et al. Sex Differences in the Renal Function Decline of Patients with Type 2 Diabetes. J Diabetes Res 2016;2016:4626382.

6. Low SK, Sum CF, Yeoh LY, et al. Prevalence of Chronic Kidney Disease in Adults with Type 2 Diabetes Mellitus. 
Ann Acad Med Singap 2015;44:164-71.

7. Sacks FM, Hermans MP, Fioretto P, et al. Association Between Plasma Triglycerides and High-Density Lipoprotein Cholesterol and Microvascular Kidney Disease and Retinopathy in Type 2 Diabetes Mellitus A Global Case-Control Study in 13 Countries. Circulation 2014;129:999-1008.

8. Zhang L, Long J, Jiang W, et al. Trends in Chronic Kidney Disease in China. N Engl J Med 2016;375:905-6.

9. Jia W, Gao X, Pang C, et al. Prevalence and risk factors of albuminuria and chronic kidney disease in Chinese population with type 2 diabetes and impaired glucose regulation: Shanghai diabetic complications study (SHDCS). Nephrol Dial Transplant 2009;24:3724-31.

10. Xu R, Zhong YH, Chen B, et al. The prevalence and risk factors of kidney disease in type 2 diabetic patients in rural Shanghai. Zhonghua Nei Ke Za Zhi 2012;51:18-23.

11. Duan J, Wang C, Liu D, et al. Prevalence and risk factors of chronic kidney disease and diabetic kidney disease in Chinese rural residents: a cross-sectional survey. Sci Rep 2019;9:10408.

12. Zhang Y, Gu YA, Wang N, et al. Association between anthropometric indicators of obesity and cardiovascular risk factors among adults in Shanghai, China. BMC Public Health 2019;19:1035.

13. Alberti KG, Zimmet PZ. Definition, diagnosis and classification of diabetes mellitus and its complications. Part 1: diagnosis and classification of diabetes mellitus provisional report of a WHO consultation. Diabet Med 1998;15:539-53.

14. Levin A, Stevens PE, Bilous RW, et al. Kidney disease: Improving global outcomes (KDIGO) CKD work group. KDIGO 2012 clinical practice guideline for the evaluation and management of chronic kidney disease. Kidney Int Suppl 2013;3:1-150.

15. Chinese eGFR Investigation Collaboration. Modification and evaluation of MDRD estimating equation for Chinese patients with chronic kidney disease. Chinese Journal of Nephrology 2006;22:589-95.

16. Liu LS; Writing Group of 2010 Chinese Guidelines for the Management of Hypertension. 2010 Chinese guidelines for the management of hypertension. Zhonghua Xin Xue Guan Bing Za Zhi 2011;39:579-615.

17. Multidisciplinary Expert Task Force on Hyperuricemia and Related Diseases. Chinese Multidisciplinary Expert Consensus on the Diagnosis and Treatment of Hyperuricemia and Related Diseases. Chin Med J (Engl) 2017;130:2473-88.
18. Joint Committee for Developing Chinese guidelines on Prevention and Treatment of Dyslipidemia in Adults. Chinese guidelines on prevention and treatment of dyslipidemia in adults. Zhonghua Xin Xue Guan Bing Za Zhi 2007;35:390-419.

19. Obesity: preventing and managing the global epidemic. Report of a WHO consultation. World Health Organ Tech Rep Ser 2000;894:i-xii, 1-253.

20. de Boer IH, Rue TC, Hall YN, et al. Temporal trends in the prevalence of diabetic kidney disease in the United States. JAMA 2011;305:2532-9.

21. Yu MK, Katon W, Young BA. Associations between sex and incident chronic kidney disease in a prospective diabetic cohort. Nephrology 2015;20:451-8.

22. Coll-de-Tuero G, Mata-Cases M, Rodriguez-Poncelas A, et al. Chronic kidney disease in the type 2 diabetic patients: prevalence and associated variables in a random sample of 2642 patients of a Mediterranean area. BMC Nephrol 2012;13:87.

23. Du Y, Pan T, Zhong X, et al. Study on the relationship between serum uricacid level and body mass index, blood lipids and renal functionin postmenopausal women with type 2 diabetes mellitus. Acta Universitatis Medicinalis Anhui 2017;52:1219-23.

24. Shen Y, Cai R, Sun J, et al. Diabetes mellitus as a risk factor for incident chronic kidney disease and end-stage renal disease in women compared with men: a systematic review and meta-analysis. Endocrine 2017;55:66-76.

25. de Hauteclocque A, Ragot S, Slaoui Y, et al. The influence of sex on renal function decline in people with Type 2 diabetes. Diabet Med 2014;31:1121-8.

26. Hanai K, Babazono T, Yoshida N, et al. Gender differences in the association between HDL cholesterol and the progression of diabetic kidney disease in type 2 diabetic patients. Nephrol Dial Transplant 2012;27:1070-5.

27. O'Hare AM, Choi AI, Bertenthal D, et al. Age affects outcomes in chronic kidney disease. J Am Soc Nephrol 2007;18:2758-65.

28. Liu Z, Albanese E, Li S, et al. Chronic disease prevalence and care among the elderly in urban and rural Beijing, China - a 10/66 Dementia Research Group cross-sectional survey. BMC Public Health 2009;9:394.

29. Shankar A, Klein R, Klein BE. The association among smoking, heavy drinking, and chronic kidney disease. Am J Epidemiol 2006;164:263-71.

30. Staplin N, Haynes R, Herrington WG, et al. Smoking and Adverse Outcomes in Patients With CKD: The Study of Heart and Renal Protection (SHARP). Am J Kidney Dis 
2016;68:371-80.

31. Kao WH, Puddey IB, Boland LL, et al. Alcohol consumption and the risk of type 2 diabetes mellitus: atherosclerosis risk in communities study. Am J Epidemiol 2001;154:748-57.

32. Vupputuri S, Sandler DP. Lifestyle risk factors and chronic kidney disease. Ann Epidemiol 2003;13:712-20.

33. Savdie E, Grosslight GM, Adena MA. Relation of alcohol and cigarette consumption to blood pressure and serum creatinine levels. J Chronic Dis 1984;37:617-23.

34. Matsumoto A, Nagasawa Y, Yamamoto R, et al. The association of alcohol and smoking with CKD in a Japanese nationwide cross-sectional survey. Hypertens Res 2017;40:771-8.

35. Schaeffner ES, Kurth T, de Jong PE, et al. Alcohol consumption and the risk of renal dysfunction in apparently healthy men. Arch Intern Med 2005; 165:1048-53.

36. Wang S, Shu Z, Tao Q, et al. Uric acid and incident

Cite this article as: Yang Y, Wang N, Jiang Y, Zhao Q, Chen Y, Ying X, Zhao G, Fu C. The prevalence of diabetes mellitus with chronic kidney disease in adults and associated factors in Songjiang District, Shanghai. Ann Palliat Med 2021;10(7):72147224. doi: 10.21037/apm-21-803 chronic kidney disease in a large health check-up population in Taiwan. Nephrology (Carlton) 2011;16:767-76.

37. Johnson RJ, Segal MS, Srinivas T, et al. Essential hypertension, progressive renal disease, and uric acid: a pathogenetic link? J Am Soc Nephrol 2005;16:1909-19.

38. Slinin Y, Ishani A, Rector T, et al. Management of hyperglycemia, dyslipidemia, and albuminuria in patients with diabetes and CKD: a systematic review for a KDOQI clinical practice guideline. Am J Kidney Dis 2012;60:747-69.

39. Lorber D, Reddan D. Clinical characteristics of chronic kidney disease patients with and without diabetes: a subanalysis of the PAERI study. Clin Nephrol 2006;66:11-6.

40. Lv Y, Li S, Zhang S, et al. Insulin resistance and endothelial dysfunction in different period diabetic nephropathy. Chinese Journal of Gerontology 2007;(7):647-50. 